\title{
In vitro selenium accessibility in pet foods is affected by diet composition and type
}

\author{
Mariëlle van Zelst ${ }^{1}$, Myriam Hesta ${ }^{1}$, Lucille G. Alexander ${ }^{2}$, Kerry Gray ${ }^{2}$, Guido Bosch ${ }^{3}$, \\ Wouter H. Hendriks ${ }^{3,4}$, Gijs Du Laing ${ }^{5}$, Bruno De Meulenaer ${ }^{6}$, Klara Goethals ${ }^{7}$ and Geert P. J. Janssens ${ }^{1 *}$ \\ ${ }^{1}$ Department of Animal Nutrition, Genetics and Ethology, Faculty of Veterinary Medicine, Ghent University, \\ Merelbeke, Belgium \\ ${ }^{2}$ WALTHAM ${ }^{\circledR}$ Centre for Pet Nutrition, Waltham-on-the-Wolds, Leicestershire, UK \\ ${ }^{3}$ Animal Nutrition Group, Department of Animal Sciences, Wageningen University, Wageningen, The Netherlands \\ ${ }^{4}$ Department of Animal Nutrition, Faculty of Veterinary Medicine, Utrecht University, Utrecht, The Netherlands \\ ${ }^{5}$ Department of Applied Analytical \& Physical Chemistry, Faculty of Bioscience Engineering, Ghent University, \\ Ghent, Belgium \\ ${ }^{6}$ Department of Food Safety \& Food Quality, Faculty of Bioscience Engineering, Ghent University, Ghent, Belgium \\ ${ }^{7}$ Department of Comparative Physiology E Biometrics, Faculty of Veterinary Medicine, Ghent University, Merelbeke, Belgium
}

(Submitted 29 January 2015 - Final revision received 13 March 2015 - Accepted 26 March 2015 - First published online 21 May 2015)

\begin{abstract}
Se bioavailability in commercial pet foods has been shown to be highly variable. The aim of the present study was to identify dietary factors associated with in vitro accessibility of $\mathrm{Se}\left(\mathrm{Se} \mathrm{A}_{\mathrm{iv}}\right)$ in pet foods. Se $\mathrm{A}_{\mathrm{iv}}$ is defined as the percentage of Se from the diet that is potentially available for absorption after in vitro digestion. Sixty-two diets (dog, $n 52$; cat, $n 10)$ were in vitro enzymatically digested: fifty-four of them were commercially available (kibble, $n$ 20; pellet, $n$ 8; canned, $n$ 17; raw meat, $n$ 6; steamed meat, $n$ 3) and eight were unprocessed (kibble, $n$ 4; canned, $n$ 4) from the same batch as the corresponding processed diets. The present investigation examined if Se $\mathrm{A}_{\mathrm{iv}}$ was affected by diet type, dietary protein, methionine, cysteine, lysine and Se content, DM, organic matter and crude protein (CP) digestibility. Se $\mathrm{A}_{\mathrm{iv}}$ differed significantly among diet types $(P<0 \cdot 001)$. Canned and steamed meat diets had a lower Se $\mathrm{A}_{\mathrm{iv}}$ than pelleted and raw meat diets. Se $\mathrm{A}_{\mathrm{iv}}$ correlated positively with $\mathrm{CP}$ digestibility in extruded diets (kibbles, $n 19 ; r 0.540, P=0.017$ ) and negatively in canned diets ( $n 16 ; r-0 \cdot 611, P=0 \cdot 012)$. Moreover, the canning process $(n 4)$ decreased Se $\mathrm{A}_{\mathrm{iv}}(P=0 \cdot 001)$, whereas extrusion $(n 4)$ revealed no effect on Se $\mathrm{A}_{\mathrm{iv}}(P=0 \cdot 297)$. These differences in Se $\mathrm{A}_{\mathrm{iv}}$ between diet types warrant quantification of diet type effects on in vivo Se bioavailability.
\end{abstract}

\section{Key words: Selenium: Bioaccessibility: Dogs: Processing effects: In vitro digestion}

Se is an essential micronutrient that is required by dogs and cats to sustain the basic functions of life, such as antioxidant, immune and thyroid functions ${ }^{(1)}$. There is a large variability in Se content within and between raw materials used in pet foods $^{(2)}$. For example beef muscle contains on average $11.9 \mu \mathrm{g} \mathrm{Se} / \mathrm{MJ}$ with a range of 6.6-22.0 $\mathrm{gg} \mathrm{Se} / \mathrm{MJ}$, and whole grain wheat contains on average $1.7 \mu \mathrm{g} \mathrm{Se} / \mathrm{MJ}$, ranging between 0.8 and $4.6 \mu \mathrm{g} \mathrm{Se} / \mathrm{MJ}^{(2)}$. Moreover, the bioavailable Se fraction, i.e. the Se fraction that reaches the systemic circulation $^{(3)}$, can also vary considerably between raw ingredients and processed pet foods, although information available is limited. Wedekind et al. ${ }^{(4)}$ used a chicken bioassay and found that Se bioavailability (BA) of pet food ingredients, relative to $\mathrm{Na}_{2} \mathrm{SeO}_{3}$, ranged from $9 \%$ in mackerel to $38 \%$ in beef spleen; these authors found the Se BA in canned dog and cat foods to be 25 and $17 \%$, respectively. Using the same methodology, subsequent studies reported ${ }^{(5)}$ greater relative Se BA of canned (30\%) and dry pet foods (53\%) respectively. Todd et al. ${ }^{(6,7)}$ reported the Se BA of two canned cat foods, as measured in Se balance studies in adult cats, to be $25 \cdot 3$ and $21 \cdot 2 \%$, respectively. The reason for these variable and often low values is unknown.

There are several factors that might underlie variations in Se BA. An important factor is the chemical form of Se: organic Se gets absorbed in the intestine through active transport, whereas sodium selenite appears to get absorbed through

Abbreviations: BA, bioavailability; CP, crude protein; Cys, cysteine; Lys, lysine; Met, methionine; Se $\mathrm{A}_{\mathrm{iv}}$, in vitro accessibility of Se; TDF, total dietary fibre. 
diffusion $^{(8)}$. Due to competition for absorption sites, $\mathrm{S}$ and methionine (Met) can also influence Se absorption ${ }^{(3,9)}$. Moreover, Se BA might also be affected by factors such as fibre content ${ }^{(10-14)}$ and food processing ${ }^{(15,16)}$, due to their effect on overall nutrient digestibility. Dietary fat is another potential factor, since it correlates negatively with the concentration of Se containing enzymes (glutathione peroxidase) in plasma of chickens ${ }^{(17)}$, suggesting that dietary fat reduces the intestinal transport of Se. In vitro, dietary fat is also negatively associated with Se accessibility ( $S e \mathrm{~A}_{\mathrm{iv}}$ ), i.e. the dietary Se fraction in the filtrate after in vitro digestion, in milk ${ }^{(18)}$.

The aim of the present study was to identify dietary factors that affect the Se $\mathrm{A}_{\mathrm{iv}}$ in commercial pet foods. Se $\mathrm{A}_{\mathrm{iv}}$ was used as an estimate for Se BA. For this study, sixty-two pet foods were selected based on their variability in nutrient content and diet type.

\section{Experimental methods}

\section{Diet selection}

A set of fifty-four commercial (dog, $n$ 44; cat, $n$ 10) and eight unprocessed pet foods were sourced to meet a broad range of diet types (kibble (extruded), $n$ 24; pellet (pressed), $n$; can (retorted), $n$ 21; meat, $n$ 9, (six raw/frozen and three steamed)) and nutrient composition (protein content, mean $34.4 \%$ of DM, range $7 \cdot 9-93.8 \%$; fat content, mean $20.7 \%$ of $\mathrm{DM}$, range $3 \cdot 1-52 \cdot 4 \%$; and fibre content, mean $4.0 \%$ of DM, range $0 \cdot 7-13 \cdot 2 \%)$. A broad range in nutrient composition was achieved based on listing label information of the parameters mentioned above. A small number of cat foods were included to broaden the range of dietary protein content. The number of diets per diet type was chosen to reflect the market availability of these diet types. Diet types differed by virtue of both their processing (heat and pressure treatment) and raw ingredients (cereals, fresh meat products, meat and/or bone meal). As the majority of pet food producers did not include Se content or speciation on the package or website, this information was not available for diet selection. It is possible that diet types differ in their typical amount and speciation of Se, but this was considered as an inherent trait of the diet types.

In addition to the commercially available diets, eight standard recipes of unprocessed diets (kibble, $n$ 4; can, $n$ 4) were included in the diet selection to assess the effect of processing. The unprocessed diets came from the same batch as the corresponding commercially available diet that was selected. Each of the sixty-two diets was analysed for DM, crude ash, crude protein $(\mathrm{CP}, 6.25 \times \mathrm{N})$, crude fat, S, amino acid profile, total dietary fibre (TDF), gross energy and total Se (methodologies as described in 'Chemical analyses').

\section{Sample preparation}

Dry diets were ground over a $1 \mathrm{~mm}$ sieve in a centrifugal mill (Retsch ZM200; Retsch GmbH). The wet diets (canned and meat) were homogenised using a hand mixer (Philips HR1561), and then frozen at $-20^{\circ} \mathrm{C}$ until in vitro digestion.
A portion of each wet diet was also freeze-dried and ground over a $1 \mathrm{~mm}$ sieve for chemical analyses.

\section{In vitro digestion}

Stomach and small intestinal digestion were simulated using a modified procedure described by Hervera et al. ${ }^{(19)}$. The method consisted of a $2 \mathrm{~h}$ pepsin (2000 International Pharmaceutical Federation (FIP) U/g, expressed as $\mu \mathrm{mol}$ of tyrosine equivalents liberated per min at $25^{\circ} \mathrm{C}$, Merck article. no. 7190) incubation step at a $\mathrm{pH}$ of $2 \cdot 0$, and a second pancreatin (porcine pancreas grade VI, Sigma no. P-1750) incubation step for $4 \mathrm{~h}$ at a $\mathrm{pH}$ of 6.8 . The method was scaled up tenfold to increase the amount of residue required for chemical analyses. The amount of fresh matter required that equated to $10 \mathrm{~g}$ of DM ( \pm 0.75$)$ was calculated, to account for the different moisture contents of each diet. De-mineralised water was added to all diets to achieve a moisture content of $85 \%$. A hypoxic environment was used by addition of $\mathrm{CO}_{2}$ for $30 \mathrm{~s}$ before every incubation step, to prevent Se oxidation, which might have an influence on the $\mathrm{Se} \mathrm{A}_{\mathrm{iv}}^{(20-22)}$. Glass covers were placed over the beakers during incubation, and $\mathrm{pH}$ was measured after every incubation step. As dietary fat content may influence Se $\mathrm{A}_{\mathrm{iv}}^{(18)}$, samples were not defatted before incubation, as was done in the original method, but $1.5 \mathrm{~g}$ bile extract (Sigma Porcine Bile Extract B8631; Sigma Aldrich) was added to the small intestine incubation step to mimic fat digestion. Type and amount of bile extract is based on publications of Hedrén et al. ${ }^{(23)}$, Clegg et $a l^{(24)}$ and Intawongse \& Dean $^{(25)}$. Due to the larger amount of the sample, the filtration step as described by Hervera et al. ${ }^{(19)}$ was not feasible. Filtration was performed with a Büchner funnel and a nylon cloth, based on a method of Jha et al. ${ }^{(26)}$, resulting in a digested (filtrate) and undigested (residue) fraction.

The filtrates were stored at $-20^{\circ} \mathrm{C}$ for total Se analysis. Residues were scraped from the cloth and dried overnight in an oven at $70^{\circ} \mathrm{C}$ and stored at room temperature. Residues were pooled per diet and ground to a powder before analyses for DM, crude ash and CP. In order to obtain at least $3 \mathrm{~g}$ of residue for analyses, in vitro digestion was repeated two to nine times according to the digestibility of the diets. Diets with an in vitro DM digestibility higher than $97 \%$ were eliminated from the study, because more than ten repeats would have been necessary. With every new batch of buffers, quality controls (blanks and one of the pelleted study diets) were incubated for assessment of repeatability between runs. The $\mathrm{CV}$ for $\mathrm{DM}$ digestibility over the incubation runs was $0.5 \%$. Diet filtrates were corrected for total Se in the blank filtrates $(2.31 \mu \mathrm{g} / \mathrm{l}$, only containing de-mineralised water, buffers, pepsin, pancreatin and bile solutions).

\section{Chemical analyses}

Diet sample preparation for total Se analysis was adapted from Lavu et $a l .{ }^{(27)}$. Diets were prepared using closed-vessel microwave acid digestion. $1 \mathrm{~g}$ of each sample with an accuracy of 0.03 was weighed into a vessel, and $10 \mathrm{ml}$ nitric acid $65 \%$ was added. Vessels were closed and placed into a microwave 
(MARS 5 CEM) for $25 \mathrm{~min}$ in total $\left(1200 \mathrm{~W}, 600 \mathrm{psi}, 195^{\circ} \mathrm{C}\right.$ for $13 \mathrm{~min})$. Vessels were cooled and the contents were filtered over a no. 42 Whatman filter paper into a $50 \mathrm{ml}$ flask, and diluted with ultra-pure water up to $50 \mathrm{ml}$. Filtrates resulting from the in vitro digestion were pooled per sample and transferred into a $20 \mathrm{ml}$ centrifuge tube. Samples were centrifuged for $10 \mathrm{~min}$ at $10000 \mathrm{~g}$ (Sorvall RC-5B Refrigerated Superspeed Centrifuge, SA-600 rotor; DuPont Instruments). Supernatants were pipetted into $1.5 \mathrm{ml}$ Eppendorf tubes and stored at $-20^{\circ} \mathrm{C}$ until analysis. Samples were analysed for total Se using inductively coupled plasma-MS (Elan DRC-e; PerkinElmer), as described by Lavu et al. ${ }^{(27)}$. Spikes with Certipur ${ }^{\circledR}$ selenium standard solution $\left(\mathrm{SeO}_{2}\right.$ in $\mathrm{HNO}_{3}, 1000 \mathrm{mg} \mathrm{Se} / \mathrm{l}$, Merck Art no. 119796) at a concentration of 200 or $400 \mu \mathrm{g} / \mathrm{l}$ were added as a quality control to four samples before and three samples after microwave destruction. Se recoveries of $87.7 \%$ (SD $1.1 \%$ ) and $82.6 \%$ (SD $4.5 \%$ ) were obtained when spikes were added after or before microwave destruction, respectively.

Diets and residues were analysed in duplicate for DM and crude ash, by drying to a constant weight at $103^{\circ} \mathrm{C}$ and combusting at $550^{\circ} \mathrm{C}$, respectively. The Kjeldahl method (ISO 5983-1, $2005)^{(28)}$ was used to determine CP $(6.25 \times \mathrm{N})$. Crude fat in the diets was assayed according to the Berntrop-method (ISO $6492,1999)^{(29)}$, and gross energy was analysed by bomb calorimetry. The microwave digests prepared for Se analyses in diets, were also analysed for $\mathrm{S}$ using inductively coupled plasmaoptical emission spectrometry (ICP-OES, Iris intrepid II XSP, Thermo Fisher Scientific, Inc.) according to ISO 11885 $(2007)^{(30)}$. Diets were defatted by fat extraction with petroleum diethyl ether and extracted in line with the procedure of the Commission Directive $(98 / 64 / \mathrm{EC})^{(31)}$ for amino acid analyses; an HPLC method was used (Agilent 1100; Fluorescence Detector; ZORBAX eclipse AAA Rapid Resolution $4.6 \times 150 \mathrm{~mm}$, 3.5 micron column, PN 963400-902, Agilent Technologies) according to the method of Henderson et al. ${ }^{(32)}$. TDF analyses were performed using the enzymatic-gravimetric method described by Prosky et al. ${ }^{(33)}$ (AOAC 985.29).

\section{Calculations}

Se $A_{i v}$ was calculated with the following formula:

Se $A_{\text {iv }}(\%)=($ Se in the filtrate $(\mu \mathrm{g} / \mathrm{l})$

$\times($ dilution during in vitro digestion $(\mathrm{ml}) / 1000)$ )/

sample weighed in for in vitro digestion

$(\mathrm{g} \mathrm{DM}) \times 100 /$ Se in the $\operatorname{diet}(\mu \mathrm{g} / \mathrm{g} \mathrm{DM})$.

Digestibility coefficients were calculated with the formulae:

DM digestibility $(\%)=100-($ residue $(\mathrm{g} \mathrm{DM}) \times 100 /$ sample weighed in for in vitro digestion (g DM)).

Organic matter digestibility $(\%)=100-($ residue $(\mathrm{g} \mathrm{DM})$ $\times(100-$ ash in residue $(\% \mathrm{DM})) / 100) \times 100 /$ (sample weighed in for in vitro digestion $(\mathrm{g} \mathrm{DM}) \times(100-$ ash in the $\operatorname{diet}(\% \mathrm{DM})) / 100)$.

$$
\begin{aligned}
\mathrm{CP} \text { digestibility }(\%)= & 100-(\mathrm{CP} \text { in the residue }(\mathrm{g} \mathrm{DM}) \times 100 / \\
& \mathrm{CP} \text { in the sample weighed in for in vitro } \\
& \text { digestion }(\mathrm{g} \mathrm{DM})) .
\end{aligned}
$$

\section{Statistical analyses}

Data were analysed using the Statistical Analysis System (SAS) version 9.3 for Windows (SAS Institute, Inc.). Data were initially screened for linearity, normality, outliers and homogeneity of variance. The effect of diet type on Se $\mathrm{A}_{\mathrm{iv}}$ was analysed using ANOVA (PROC GLM). Pairwise comparisons between diet types were tested at a total significance level of 0.05 using the Tukey-Kramer adjustment for multiple comparisons. The effect of the variables gross energy, CP, fat, TDF, S, Se, lysine (Lys), cysteine (Cys) and Met of the diets, and calculated variables CP (g/MJ), Met/CP, Met (g/MJ), Cys/CP, Cys (g/MJ), Lys/CP, Lys $(\mathrm{g} / \mathrm{MJ})$, Se $(\mu \mathrm{g} / \mathrm{MJ})$, DM digestibility, organic matter digestibility and CP digestibility on Se $\mathrm{A}_{\mathrm{iv}}$ was analysed, per diet type, using regression (PROC REG). The effect of processing was analysed with a paired Student's $t$ test. In all cases statistical significance was evaluated at $P \leq 0 \cdot 05$.

\section{Results}

One commercial canned diet and one commercial extruded diet were eliminated for further analyses based on an in vitro DM digestibility $>97 \%$. The inter-assay CV for DM digestibility over the incubation runs was $0.5 \%$ and $\mathrm{pH}$ remained constant within each incubation step. Total Se in the blank samples was on average $2.31 \mu \mathrm{g} / 1$, which was used to correct Se in filtrates. Se analyses had a recovery of $87.7 \%$ as measured using spiked samples after microwave destruction, and $82.6 \%$ when samples were spiked before microwave destruction. Table 1 provides an overview of the chemical composition and digestibility results of the diets per diet type. The high variation in CP, crude fat and TDF reflect the diet selection criteria. The large range in Se content of the diets was mainly due to two high values from raw meat diets $(1173.2$ and $1195.5 \mu \mathrm{g} / 100 \mathrm{~g} \mathrm{DM})$, which also increased the mean value over all diets $(98.4 \mu \mathrm{g} / 100 \mathrm{~g} \mathrm{DM}$, results not shown). The median for dietary Se overall diets was 44.8 $\mu \mathrm{g} / 100 \mathrm{~g}$ DM (results not shown).

Se $\mathrm{A}_{\mathrm{iv}}$ differed among diet types $(P<0.001$; Table 2$)$. Canned and steamed meat diets had lower Se $\mathrm{A}_{\mathrm{iv}}$ than pelleted and raw meat diets. In all diet types, a large range of Se $\mathrm{A}_{\mathrm{iv}}$ was found, but the range was the largest for kibble and canned diets. There was no significant correlation between Se $\mathrm{A}_{\mathrm{iv}}$ and $\mathrm{CP}$ digestibility when all diet types were pooled (Fig. 1; $r-0.095, P=0.504)$. However, when diet type was considered, there was a positive correlation between Se $\mathrm{A}_{\mathrm{iv}}$ and in vitro $\mathrm{CP}$ digestibility in the kibble diets ( $r$ 0.540, $P=0.017) \quad v$. a negative correlation in the canned diets $(r-0.611, P=0.012)$.

Se $A_{i v}$ was not significantly correlated with any of the measured parameters in the pelleted diets. Raw meat diets showed a negative correlation between the amount of Se in the diet and the Se $\mathrm{A}_{\mathrm{iv}}$ (in $\mu \mathrm{g} / \mathrm{g} \mathrm{DM}: r-0.823, P=0.044$; 
Table 1. Chemical composition (g/100 g DM, except where specified), gross energy content (MJ/kg DM) and in vitro digestibility (\%, w/w) of pet foods ( $n$ 60) per diet type

(Mean values and standard deviations)

\begin{tabular}{|c|c|c|c|c|c|c|c|c|c|c|}
\hline \multirow[b]{2}{*}{ Component } & \multicolumn{2}{|c|}{ Kibble $(n 23)^{*}$} & \multicolumn{2}{|c|}{ Pellet $(n 8)$} & \multicolumn{2}{|c|}{ Canned $(n 20)^{\star}$} & \multicolumn{2}{|c|}{ Raw meat $(n 6)$} & \multicolumn{2}{|c|}{$\begin{array}{c}\text { Steamed meat } \\
(n 3)\end{array}$} \\
\hline & Mean & SD & Mean & SD & Mean & SD & Mean & SD & Mean & SD \\
\hline $\mathrm{DM}$ ( $\mathrm{g} / 100 \mathrm{~g}$ as is) & $92 \cdot 3$ & 1.4 & $90 \cdot 7$ & 0.7 & $24 \cdot 6$ & $7 \cdot 6$ & $35 \cdot 4$ & $3 \cdot 1$ & $27 \cdot 3$ & $4 \cdot 1$ \\
\hline Crude ash & 7.5 & 1.8 & $7 \cdot 6$ & 1.4 & 8.9 & 3.0 & 6.9 & $2 \cdot 5$ & $11 \cdot 2$ & $1 \cdot 1$ \\
\hline Crude protein $(\mathrm{N} \times 6.25)$ & 30.9 & 11.4 & $24 \cdot 1$ & $5 \cdot 0$ & $42 \cdot 6$ & $17 \cdot 8$ & $38 \cdot 0$ & $4 \cdot 2$ & $45 \cdot 6$ & $5 \cdot 0$ \\
\hline Lys & 1.5 & 0.7 & $1 \cdot 2$ & 0.5 & 2.4 & 1.4 & $2 \cdot 3$ & 0.3 & $3 \cdot 3$ & 0.5 \\
\hline Met & 0.5 & 0.2 & 0.3 & 0.2 & 0.9 & 0.5 & 0.8 & $0 \cdot 1$ & $1 \cdot 1$ & 0.2 \\
\hline Cys & 2.9 & 1.0 & $2 \cdot 3$ & 0.6 & 4.3 & 1.8 & 4.4 & 0.4 & $5 \cdot 6$ & $1 \cdot 2$ \\
\hline Crude fat & $14 \cdot 6$ & 4.9 & $13 \cdot 1$ & $2 \cdot 8$ & $20 \cdot 9$ & $7 \cdot 7$ & $39 \cdot 1$ & 3.5 & $36 \cdot 6$ & 3.9 \\
\hline Total dietary fibre & $12 \cdot 6$ & $4 \cdot 8$ & $13 \cdot 1$ & $5 \cdot 7$ & 10.5 & 3.6 & $13 \cdot 6$ & 4.5 & $11 \cdot 3$ & 0.8 \\
\hline $\mathrm{S}(\mathrm{mg} / 100 \mathrm{~g} \mathrm{DM})$ & $8 \cdot 0$ & 3.0 & $6 \cdot 1$ & 1.9 & $2 \cdot 6$ & $1 \cdot 2$ & $2 \cdot 8$ & 0.7 & $2 \cdot 7$ & 0.4 \\
\hline Total Se $(\mu \mathrm{g} / 100 \mathrm{~g} \mathrm{DM})$ & $47 \cdot 6$ & $24 \cdot 7$ & $39 \cdot 0$ & $15 \cdot 3$ & $81 \cdot 1$ & $66 \cdot 0$ & 461.4 & 562.9 & $36 \cdot 9$ & $4 \cdot 6$ \\
\hline Gross energy & $21 \cdot 2$ & 1.2 & $20 \cdot 4$ & 0.8 & $23 \cdot 3$ & 1.7 & $27 \cdot 6$ & $1 \cdot 1$ & $26 \cdot 2$ & 0.8 \\
\hline DM digestibility & $87 \cdot 8$ & $5 \cdot 7$ & $87 \cdot 0$ & $5 \cdot 8$ & $91 \cdot 4$ & $2 \cdot 6$ & $82 \cdot 8$ & $5 \cdot 3$ & $87 \cdot 1$ & $2 \cdot 1$ \\
\hline Organic matter digestibility & $87 \cdot 8$ & $5 \cdot 8$ & $87 \cdot 3$ & $5 \cdot 6$ & $91 \cdot 7$ & $2 \cdot 7$ & 83.1 & 5.5 & $87 \cdot 8$ & $2 \cdot 3$ \\
\hline Crude protein digestibility & $93 \cdot 0$ & 3.9 & $93 \cdot 3$ & $2 \cdot 1$ & 95.9 & $2 \cdot 1$ & $92 \cdot 1$ & $3 \cdot 1$ & $96 \cdot 4$ & 0.4 \\
\hline
\end{tabular}

* Including four unprocessed diets.

in $\mu \mathrm{g} / \mathrm{MJ}: r-0.843, P=0.035)$. For the steamed meat diets a positive correlation was found between $\mathrm{Se} \mathrm{A}_{\mathrm{iv}}$ and the amount of Cys per MJ ( $r$ 0.999, $P=0.012)$. The correlations for the canned and kibble diets are displayed in Table 3. Among the kibble diets a negative correlation was found between Se $\mathrm{A}_{\mathrm{iv}}$ and dietary CP, Lys, Cys, Met, S, ash, CP/MJ, Cys/MJ, and Lys/MJ. In canned diets Se $\mathrm{A}_{\mathrm{iv}}$ was negatively correlated with dietary TDF.

The extrusion process did not affect Se $A_{\mathrm{iv}}(P=0 \cdot 297$, Table 4). In contrast, retorting almost halved Se $\mathrm{A}_{\mathrm{iv}}$ $(P=0 \cdot 001)$. Dietary Se concentrations did not differ before and after processing (canned $P=0.863$, kibble $P=0.335$; results not shown). In the canned diets, the $S$ content was higher before processing $(P=0.028)$, and the TDF content tended to be higher after processing $(P=0.085)$

\section{Discussion}

To verify the factors that may contribute to the Se BA of pet foods, the present study examined a large range of commercially available pet foods differing in diet type and protein, fat and fibre content. There was a clear difference in Se $\mathrm{A}_{\mathrm{iv}}$ between diet types (canned and steamed meat Se $\mathrm{A}_{\mathrm{iv}}<$ pellet and raw meat $\mathrm{Se} \mathrm{A}_{\mathrm{iv}}$ ) which may have been due to the way the diets were processed. A number of factors such as time, temperature, pressure and shear that influence the processing of pet foods may have contributed to the observed variation. Typically, raw meat diets and pelleted diets, which undergo no or relatively low heat treatment, showed a higher Se $A_{i v}$ (91 and $79 \%$, respectively), compared to steamed meat and canned diets (47 and 58\%, respectively). These findings suggest a negative effect of heat processing on Se accessibility. This is in accordance with findings of Todd ${ }^{(16)}$, who found that non-processed inorganic Se in canned diets had a higher apparent Se absorption in cats $(83.3 \%)$ than processed inorganic Se $(53.7 \%)^{(16)}$. Canned diets had a higher Se $A_{i v}$ before, compared to after processing, which also indicates an effect of processing on $\mathrm{Se} \mathrm{A}_{\mathrm{iv}}$, which was not demonstrated in the kibble diets. The differences in the effect of processing on Se $\mathrm{A}_{\mathrm{iv}}$ between canned and kibble diets may be due to variations in Maillard reactions caused by the different processing types. In the baking process, some Se may be lost because the Maillard reaction of selenomethionine and glucose yields volatile seleniferous compounds ${ }^{(34)}$. This did not appear to have a major influence on total Se in the present study, because total dietary Se did not differ before and after processing. Processing did decrease the S content in canned diets, which might be due to the conversion of dietary $S$ to volatile compounds and volatilisation after opening the processed cans. Another possible effect in heat-processed diets is the occurrence of cross-linkages between amino acids, within and between proteins. Cross-linking reduces the rate of protein digestion by preventing enzyme penetration, or by masking the sites of enzyme attack ${ }^{(35)}$. Cys seems to be one of the most susceptible amino acids for cross-linking ${ }^{(36)}$, by which Se linked to Cys might be less available for digestion.

Hendriks et al. ${ }^{(15)}$ showed that heat processing a cat food at $121^{\circ} \mathrm{C}$ for $80-120 \mathrm{~min}$ did not destroy amino acids, but did decrease ileal apparent digestibility of the diet. In the present study, there was no impact on $\mathrm{CP}$ digestibility, when

Table 2. In vitro selenium accessibility of pet foods $(\%, w / w)$ per diet type

(Mean values and standard deviations; number of animals, minimum and maximum values)

\begin{tabular}{lrcccc}
\hline Diet type & $n$ & Mean & SD & Minimum & Maximum \\
\hline Kibble $^{*}$ & 19 & 72 & 17 & 37 & 97 \\
Pellet & 8 & 79 & 13 & 62 & 101 \\
Canned & 16 & 58 & 16 & 29 & 91 \\
Raw meat & 6 & 91 & 23 & 79 & 98 \\
Steamed meat & 3 & 47 & 8 & 39 & 54
\end{tabular}

* Unprocessed diets are not included in the data. 


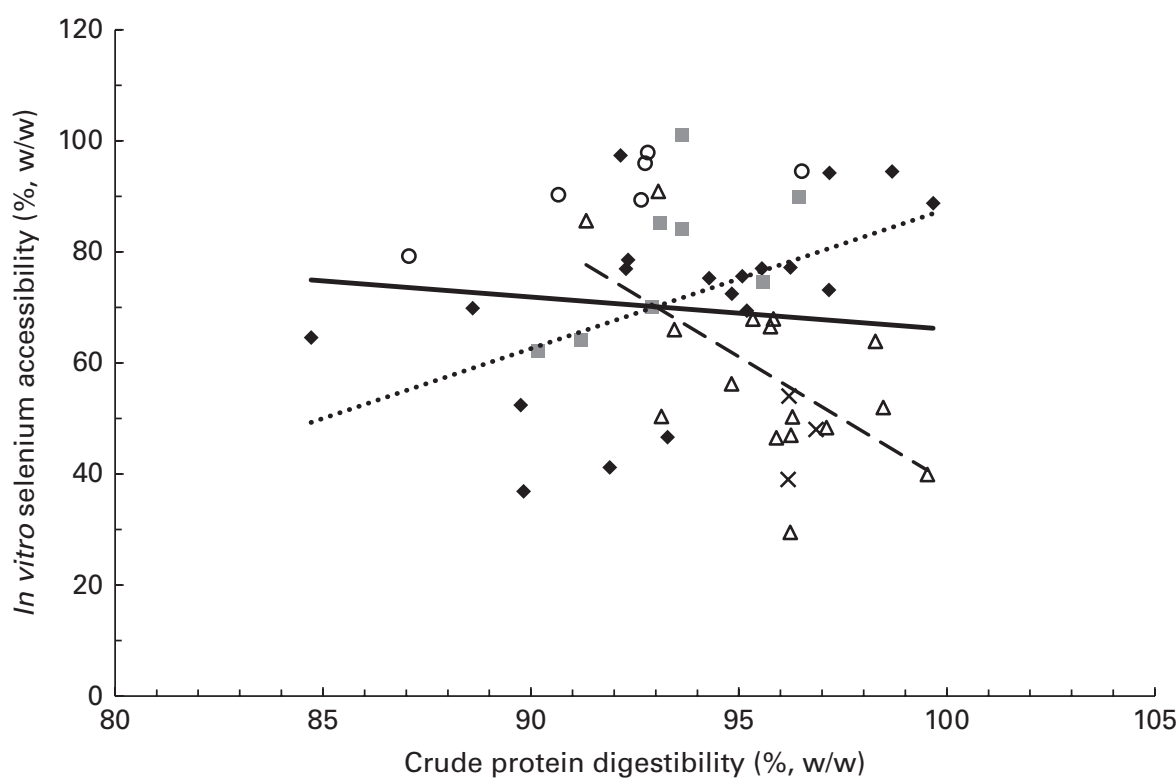

Fig. 1. Correlations $(r)$ between in vitro selenium accessibility $(\%, \mathrm{w} / \mathrm{w})$ and crude protein digestibility $(\%, \mathrm{w} / \mathrm{w})$ of pet foods: 一, all diets $(n 52, r-0.095)$; $\cdots .$. and $\$$, kibble $\left(n 19, r 0.540^{*}\right)$; $\ldots$, pellet $(n 8) ;--$ and $\Delta$, canned $\left(n 16, r-0.611^{\star}\right)$; 0 , raw meat $(n 6)$; $\times$, steamed meat $(n 3)$. ${ }^{*}$ Values show a significant correlation $(P<0.05)$. Unprocessed diets are not included in the data.

comparing the same diets pre- and post-processing. However, the effect of $\mathrm{CP}$ digestibility on Se $\mathrm{A}_{\mathrm{iv}}$ differed between canned and kibble diets. In kibble diets, there was a positive relationship between CP digestibility and Se $\mathrm{A}_{\mathrm{iv}}$. This may indicate that when more protein is digested, more protein bound-Se becomes available. Similar findings were reported by Shen et al. ${ }^{(18)}$ in milk products. Interestingly, the opposite effect was found for canned diets. The lack of correlation between Se $A_{i v}$ and Cys, Met and Lys suggests that they are not an explanation for the negative correlation between $\mathrm{CP}$ digestibility and $\mathrm{Se} \mathrm{A}_{\mathrm{iv}}$ in canned diets. Therefore, this correlation is likely due to a factor that was not accounted for in the present study.

The source of TDF in the canned diets could affect Se $A_{i v}$, because fibre is known to reduce nutrient digestibility ${ }^{(10-14)}$. TDF in canned diets in the present study was negatively correlated with Se $\mathrm{A}_{\mathrm{iv}}$, and tended to increas in canned diets after processing, compared to TDF in unprocessed diets $(P=0.085)$. Azizah \& Zainon ${ }^{(37)}$ also found an increase in TDF after roasting wheat, rice, mung beans and soyabeans at $80^{\circ} \mathrm{C}$ for $5 \mathrm{~min}$. During heat treatment, fibre-protein complexes can be formed ${ }^{(38)}$, which might be the cause for the negative impact on Se $\mathrm{A}_{\mathrm{iv}}$ and the tendency of increase in TDF. A particular TDF component that is commonly used in canned diets is the soluble NSP guar gum. Guar gum increases viscosity and has been shown to decrease the digestibility of protein in diets fed to cats ${ }^{(39)}$, which can be an additional explanation for the negative relationship between TDF and Se $A_{i v}$ in canned diets, because protein bound-Se may then become unavailable. Choe \& Kies ${ }^{(40)}$ reported an increase in faecal Se excretion by $14 \%$ and a decreased Se balance (53\%) and whole blood glutathione peroxidase activity (9\%) in human subjects, when guar gum was supplemented to a standardised diet, although, in their study both Se and guar gum were not processed.

The difference in $\mathrm{Se} \mathrm{A}_{\mathrm{iv}}$ between the diet types might also be explained by a difference in the raw materials that are used in their manufacture, and consequently, that of the Se species in the diets. Supplemental Se in the form of sodium selenite or sodium selenate is commonly employed in dry pet foods (pellet and kibble), whereas in canned diets Se is mainly present in the form of selenomethionine from raw materials. Selenomethionine is absorbed through the same active transport

Table 3. Correlations $(r)$ between in vitro selenium accessibility $(\%, \mathrm{w} / \mathrm{w})$ and parameters of kibble $(n 19)$ and canned ( $n$ 16) diets in $\mathrm{g} / 100 \mathrm{~g} \mathrm{DM}$, except where specified

\begin{tabular}{lcr}
\hline Parameter & Kibble & Canned \\
\hline DM digestibility (\%) & 0.288 & -0.205 \\
Organic matter digestibility (\%) & 0.317 & -0.169 \\
Crude protein & $-0.769^{\star \star *}$ & 0.363 \\
Crude protein (g/MJ) & $-0.752^{\star \star \star}$ & 0.389 \\
Lys & $-0.802^{\star \star *}$ & 0.161 \\
Lys (g/MJ) & $-0.808^{\star \star *}$ & 0.174 \\
Lys/crude protein & -0.077 & -0.272 \\
Cys & $-0.765^{\star \star *}$ & 0.086 \\
Cys (g/MJ) & $-0.749^{\star \star *}$ & 0.102 \\
Cys/crude protein & 0.261 & -0.382 \\
Met & $-0.480^{\star}$ & 0.230 \\
Met (g/MJ) & -0.443 & 0.245 \\
Met/crude protein & 0.237 & -0.072 \\
Se ( $\mu$ g/g DM) & -0.100 & -0.054 \\
Se ( $\mu$ g/MJ) & -0.056 & -0.063 \\
S (mg/100 g DM) & $-0.479^{*}$ & 0.039 \\
Total dietary fibre & -0.016 & $-0.548^{\star}$ \\
Crude fat & -0.052 & -0.258 \\
Crude ash & $-0.545^{\star}$ & 0.187 \\
Gross energy (MJ/kg DM) & -0.422 & -0.061 \\
\hline
\end{tabular}

Values were significantly different: ${ }^{\star} P<0.05,{ }^{\star \star \star} P<0.001$. † Unprocessed diets are not included in the data. 
Table 4. In vitro selenium accessibility $(\%, w / w)$ in processed $v$. unprocessed canned and kibble diets

(Mean values and standard deviations; number of animals, minimum and maximum values)

\begin{tabular}{lrrrcrcr}
\hline Diet category & $n$ & Mean & SD & Minimum & Maximum & $P^{\star}$ \\
\hline Unprocessed kibble & 4 & 60 & 8 & 53 & 68 & 0.297 \\
Processed kibble & 4 & 67 & 11 & 52 & 77 & \\
Unprocessed canned & 4 & 102 & 13 & 83 & 112 & 0.001 \\
Processed canned & 4 & 53 & 17 & 29 & 67 & \\
\hline
\end{tabular}

${ }^{*} P$-value from paired Student's $t$ test.

mechanism as Met, whereas sodium selenite is absorbed through diffusion ${ }^{(8)}$. Furthermore, reactions of sodium selenite with other components during storage may change its speciation, possibly to elemental $\mathrm{Se}^{(41)}$. Due to detection limit issues, Se speciation was not analysed in the present study; however, it may have an effect on the Se $\mathrm{BA}^{(6,20-22,42)}$.

Finally, the very high Se content in two of the raw meat diets could be due to the type of raw materials used. Tissues with a high rate of protein synthesis such as erythrocytes, skeletal muscle, pancreas, liver and kidney generally contain high amounts of $\mathrm{Se}^{(43)}$.

The present study aimed to identify factors that influence Se $\mathrm{A}_{\mathrm{iv}}$. It is possible that the in vitro Se $\mathrm{A}_{\mathrm{iv}}$ from the pet foods used in the present investigation may differ quantitatively from in vivo Se $\mathrm{A}_{\mathrm{iv}}$. Hervera et al. ${ }^{(44)}$ confirmed that apparent in vivo $\mathrm{CP}$ digestibility is lower than that in vitro. The current European recommended allowance set by the European Pet Food Industry Federation ${ }^{(45)}$ and the adequate intake of Se set by the National Research Council ${ }^{(1)}$ for dogs and cats only take into account a fixed Se BA percentage, despite the large number of factors that influence the BA. The Association of American Feed Control Officials ${ }^{(46)}$ does not give any information on which BA factor they have used for the recommended allowance of Se in pet foods. The results of the present study can be used to help design in vivo studies to confirm and quantify the impact of diet composition and type on $\mathrm{Se} \mathrm{A}_{\mathrm{iv}}$ as found in the present study. This may enable the pet food industry to formulate diets that meet canine Se requirements by taking into account the Se BA for each specific diet type.

\section{Conclusion}

The present study found evidence for the hypothesis that diet type and processing do affect Se $\mathrm{A}_{\mathrm{iv}}$. Among other factors, $\mathrm{CP}$ digestibility is positively correlated with $\mathrm{Se} \mathrm{A}_{\mathrm{iv}}$ in kibble diets, but negatively in canned diets, and retorting strongly decreased Se $\mathrm{A}_{\mathrm{iv}}$. Further in vivo studies are warranted to confirm these in vitro findings and to verify if recommendations of Se inclusion levels in pet foods need to take such factors into account.

\section{Acknowledgements}

The authors express their special thanks to Joachim Neri of the Department of Applied Analytical and Physical Chemistry at the Faculty of Bioscience Engineering of Ghent University for total Se analyses and to Sofie Coelus of the Department of Food Safety and Food Quality at the Faculty of Bioscience Engineering of Ghent University for assistance during amino acid analyses.

The present study is part of a PhD project funded by the WALTHAM $^{\circledR}$ Centre for Pet Nutrition (WCPN). Diets were provided for free by Royal Canin, Prins Petfoods, Happy Dog, InterPet Products, Arie Blok Diervoeding and FarmFood HE. The diets not provided by these firms were purchased from local stores. Apart from WCPN, none of these pet food companies had a role in the design, analysis or writing of this article.

The authors' responsibilities are as follows: M. v. Z, M. H., L. G. A., G. B., W. H. H. and G. P. J. J. conceived and designed the study; M. v. Z., L. G. A., G. P. J. J. and M. H. selected the study diets; M. v. Z. and G. B. conducted the in vitro experiment; M. v. Z., G. D. L. and B. D. M. were involved in the chemical analyses; M. V. Z. and Kl. Go. carried out the statistical analyses; M. v. Z., M. H., L. G. A., Ke. Gr. and G. P. J. J. interpreted the findings; M. v. Z. wrote the manuscript; M. H., L. G. A., Ke. Gr., G. B., W. H. H., G. D. L., B. D. M. and G. P. J. J. reviewed and edited the paper. All authors read and approved the final manuscript.

L. G. A. and Ke. Gr. were employed by the WALTHAM ${ }^{\circledR}$ Centre for Pet Nutrition at the time of the study. The other authors have no conflicts of interest to declare.

\section{References}

1. National Research Council (2006) Nutrient Requirements of Dogs and Cats. Washington, DC: National Academies Press.

2. Souci SW, Fachmann W \& Kraut H (2008) Food Composition and Nutrition Tables. Stuttgart: MedPharm Scientific Publishers.

3. Stahl W, van den Berg H, Arthur J, et al. (2002) Bioavailability and metabolism. Mol Aspects Med 23, 39-100.

4. Wedekind KJ, Cowell C, Combs GF Jr, et al. (1997) Bioavailability of selenium in petfood ingredients. FASEB J 11, A360.

5. Wedekind KJ, Bever RS, Combs GF Jr, et al. (1998) Is selenium addition necessary in pet foods? FASEB J 12, A823.

6. Todd SE, Thomas DG, Bosch G, et al. (2012) Selenium status in adult cats and dogs fed high levels of dietary inorganic and organic selenium. J Anim Sci 90, 2549-2555.

7. Todd SE, Thomas DG \& Hendriks WH (2011) Selenium balance in the adult cat in relation to intake of dietary sodium selenite and organically bound selenium. J Anim Physiol Anim Nutr 96, 148-158.

8. Reasbeck PG, Barbezat GO, Weber FL, et al. (1985) Selenium absorption by canine jejunum. Dig Dis Sci 30, 489-494. 
9. Wolffram S, Berger B, Grenacher B, et al. (1989) Transport of selenoamino acids and their sulfur analogues across the intestinal brush border membrane of pigs. J Nutr 119, 706-712.

10. Reeves PG, Leary PD, Gregoire BR, et al. (2005) Selenium bioavailability from buckwheat bran in rats fed a modified AIN-93G torula yeast-based diet. J Nutr 135, 2627-2633.

11. Muir HE, Murray SM, Fahey GC, et al. (1996) Nutrient digestion by ileal cannulated dogs as affected by dietary fibers with various fermentation characteristics. J Anim Sci 74, 1641-1648.

12. Fairweather-Tait SJ (1997) Bioavailability of selenium. Eur J Clin Nutr 51, S20-S23.

13. Silvio J, Harmon DL, Gross KL, et al. (2000) Influence of fiber fermentability on nutrient digestion in the dog. Nutrition 16, 289-295.

14. Smits CHM, Veldman A, Verstegen MWA, et al. (1997) Dietary carboxymethylcellulose with high instead of low viscosity reduces macronutrient digestion in broiler chickens. $J$ Nutr 127, 483-487.

15. Hendriks WH, Emmens MM, Trass B, et al. (1999) Heat processing changes the protein quality of canned cat foods as measured with a rat bioassay. J Anim Sci 77, 669-676.

16. Todd SE (2006) Metabolism of selenium in cats and dogs. $\mathrm{PhD}$ thesis, Massey University.

17. Mutanen ML \& Mykkänen HM (1984) Effect of dietary-fat on plasma glutathione-peroxidase levels and intestinalabsorption of ${ }^{75} \mathrm{Se}$-labeled sodium selenite in chicks. J Nutr 114, 829-834.

18. Shen L, Van Dael P, Luten J, et al. (1996) Estimation of selenium bioavailability from human, cow's, goat and sheep milk by an in vitro method. Int J Food Sci Nutr 47, 75-81.

19. Hervera M, Baucells MD, Blanch F, et al. (2007) Prediction of digestible energy content of extruded dog food by in vitro analyses. J Anim Physiol Anim Nutr 91, 205-209.

20. Swanson CA, Patterson BH, Levander OA, et al. (1991) Human $\left[{ }^{74} \mathrm{Se}\right]$ selenomethionine metabolism: a kinetic model. Am J Clin Nutr 54, 917-926.

21. Thomson CD \& Robinson MF (1986) Urinary and fecal excretions and absorption of a large supplement of selenium: superiority of selenate over selenite. Am J Clin Nutr 44, 659-663.

22. Young VR, Nahapetian A \& Janghorbani M (1982) Selenium bioavailability with reference to human nutrition. Am J Clin Nutr 35, 1076-1088.

23. Hedrén E, Diaz V \& Svanberg U (2002) Estimation of carotenoid accessibility from carrots determined by an in vitro digestion method. Eur J Clin Nutr 56, 425-430.

24. Clegg ME, Thondre PS \& Henry CJK (2011) Increasing the fat content of pancakes augments the digestibility of starch in-vitro. Food Res Int 44, 636-641.

25. Intawongse $M \&$ Dean JR (2008) Use of the physiologicallybased extraction test to assess the oral bioaccessibility of metals in vegetable plants grown in contaminated soil. Environ Pollut 152, 60-72.

26. Jha R, Bindelle J, Van Kessel A, et al. (2010) In vitro fibre fermentation of feed ingredients with varying fermentable carbohydrate and protein levels and protein synthesis by colonic bacteria isolated from pigs. Anim Feed Sci Technol 165, 191-200.

27. Lavu RVS, Willekens K, Vandecasteele B, et al. (2012) Fertilizing soil with selenium fertilizers: impact on concentration, speciation and bioaccessibility of selenium in leek (Allium ampeloprasum). J Agric Food Chem 60, 10930-10935.
28. International Organization for Standardization (2005) Animal Feeding Stuffs - Determination of Nitrogen Content and Calculation of Crude Protein Content - Part 1: Kjeldahl Method (ISO 5983-1). Geneva: ISO.

29. International Organization for Standardization (1999) Animal Feeding Stuffs - Determination of Fat Content (ISO 6492). Geneva: ISO.

30. International Organization for Standardization (2007) Determination of Selected Elements by Inductively Coupled Plasma Optical Emission Spectrometry (ICP-OES, ISO 11885). Geneva: ISO.

31. Commission Directive 98/64/EC (1998) Directive 71/393/EEC: establishing community methods of analysis for the determination of aminoacids, crude oils and fats, and olaquindox in feedingstuffs and amending. OJ L 257, 14-28.

32. Henderson JW, Ricker RD, Bidlingmeyer BA, et al. (2000) Application Note 5980-1193E: Rapid, Acurate, Sensitive and Reproducible HPLC Analysis of Amino Acids. Santa Clara: Agilent Technologies.

33. Prosky L, Asp NG, Furda I, et al. (1985) Determination of total dietary fiber in foods and food products - collaborative study. J Assoc Off Anal Chem 68, 677-679.

34. Tsai JD, Hiserodt RD, Ho CT, et al. (1998) Determination of volatile organic selenium compounds from the Maillard reaction in a selenomethionine-glucose model system. J Agric Food Chem 46, 2541-2545.

35. Hurrel RF \& Finot PA (1985) Effects of food processing on protein digestibility and amino acid availability. In Digestibility and Amino Acid Availability in Cereals and Oilseeds, pp. 233-246 [JW Finley and DT Hopkins, editors]. St Paul: American Association of Cereal Chemists.

36. Singh H (1991) Modification of food proteins by covalent crosslinking. Trends Food Sci Technol 2, 196-200.

37. Azizah AH \& Zainon H (1997) Effect of processing on dietary fiber contents of selected legumes and cereals. Malay J Nutr 3, 131-136.

38. Dhingra D, Michael M, Rajput H, et al. (2012) Dietary fibre in foods: a review. J Food Sci Technol 49, 255-266.

39. Harper EJ \& Siever-Kelly C (1997) The effect of fibre on nutrient availability in cats of different ages. In Proceedings of Recent Advances in Animal Nutrition in Australia, pp. 110-116. Armidale: University of New England.

40. Choe M \& Kies C (1989) Selenium bioavailability: the effect of guar gum supplementation on selenium utilization by human subjects. Nutr Rep Int 39, 557-565.

41. Stadlober M, Sager M \& Irgolic KJ (2001) Identification and quantification of selenium compounds in sodium selenite supplemented feed by HPLC-ICP-MS. Bodenkultur $\mathbf{5 2}$, $233-241$.

42. Todd SE, Thomas DG \& Hendriks WH (2012) Selenium balance in the adult cat in relation to intake of dietary sodium selenite and organically bound selenium. I Anim Physiol Anim Nutr 96, 148-158.

43. Schrauzer GN (2000) Selenomethionine: a review of its nutritional significance, metabolism and toxicity. $J$ Nutr 130, 1653-1656.

44. Hervera M, Baucells MD, González G, et al. (2009) Prediction of digestible protein content of dry extruded dog foods: comparison of methods. J Anim Physiol Anim Nutr 93, 366-372.

45. FEDIAF (2013) Nutritional Guidelines for Complete and Complementary Pet Food for Cats and Dogs. Bruxelles: European Pet Food Industry Federation.

46. AAFCO (2013) Official Publication of the Association of American Feed Control Officials. Champaign, IL: AAFCO, Inc. 